\title{
Occurrence of Antimicrobial Resistant Escherichia coli and Staphylococcus sp. in Faecal Samples of Wild Birds
}

\author{
Harshita Raghav, Kajal Jadav, Joycee Jogi, Uttam Yadav, Nidhi Rajput
}

School of Wildlife Forensic and Health, Nanaji Deshmukh Veterinary Science University, Jabalpur-482 001, Madhya Pradesh, India.

Received: October 2021

Accepted: January 2022

\begin{abstract}
Background: Microbial resistance to antibiotics is a worldwide problem in human and veterinary medicine. The principal risk factor for an increase in this situation is the extensive use of antibiotics leading to the dissemination of resistant bacteria and resistance genes. Bacteria from Wild birds are important with regard to antibiotic resistance due to diverse ecology and as reservoir of antibiotic resistant bacterial genes and potential spreaders.

Methods: In the present study, a total of total 75 faecal swabs from captive and free ranging wild birds were obtained for isolation and identification of E. coli and Staphylococcus sp. They were detected for presence of antimicrobial resistant drugs, six each, by using standard kirby- beaur disc diffusion test.

Result: Isolation rate of $E$ coli and Staphylococcus sp. was $77 \%$ each respectively. Antimicrobial susceptibility profile revealed resistance in E. coli was $25 \%$ and in Staphylococcus sp. $10 \%$. Most resistant antimicrobial in E. coli and Staphylococcus sp. was Cotrimoxazole (22\%) and Clindamycin (8.6\%) respectively. Presence of resistance in wild birds' species is an alarming situation as these are capable to transmitting resistant gene either vertically or horizontally. Regulating the usage of Antimicrobials in livestock and humans is the need of the hour.
\end{abstract}

Key words: Antimicrobial resistance, One health, Wild birds.

\section{INTRODUCTION}

Microbial resistance to antibiotics is a worldwide problem in human and veterinary medicine. Commonly, the principal risk factor for an increase in this situation is the extensive use of antibiotics leading to the dissemination of resistant bacteria and resistance genes in animals and humans (Van den Bogaard and Stobberingh, 2000). Wild birds can cause the contamination of vegetable crops either directly with faecal material, or indirectly, with pollution of irrigation water leading to dissemination of resistance. Immense treatments in breeding animals for therapy and prophylaxis of bacterial infections, inaccurate posology, antibiotics as food supplements and growth promoters in livestock sector are responsible for producing antimicrobial resistance.

Bacterial genes conferring resistance have the potential to spread and proliferate through humans, animals and the environment (O'Brien, 2002; VonWinterdorff, 2016) prompting the need for a coordinated one health approach to understand dissemination (Woolhouse et al., 2013; Hiltunen et al., 2016).

The emergence of new infectious diseases in wildlife and their potential threat as zoonoses, has increased general interest in wild birds as vectors of pathogens and their role in multi-drug resistance. A relationship has been established between the level of antimicrobial resistance in faecal bacteria from animals and the level of contact of these animals with people (Radhouani et al., 2010). In a study,
$31.8 \%$ E. coli isolates from poultry under various farming systems were producing extended spectrum betalactamases and were multiple antimicrobial resistant (Sunder et al., 2021). Contamination of the environment by the presence of multi-drug resistant bacteria of human and veterinary origin is leading to serious health concerns.

Antimicrobial resistance (AMR) has been recognized as one of the 10 most urgent global health threats by WHO. India has the highest burden of bacterial disease in the world which has led it to become world's biggest consumers of antibiotics and has been referred to as the AMR capital of the world. In 2011, the Health Ministers of the WHO SouthEast Asia Region articulated their commitment to combat drug resistance through the Jaipur Declaration.

A global action plan on antimicrobial resistance was developed at world health assembly in May, 2015, to strengthen the knowledge and evidence based through surveillance and research. An international consultation on AMR containment was held in Delhi in April, 2017 in which Union Minister of Health and Family Welfare, Govt. of India, announced the finalization of comprehensive and multisectoral action plan through Delhi Declaration on Antimicrobial Resistance in which one of the objectives is "Strengthening Monitoring and Surveillance". Presently, there are no data available for antimicrobial resistance in any wild birds of Central India. 


\section{MATERIALS AND METHODS}

Proposed work was conducted at Laboratory of School of Wildlife Forensic and Health, NDVSU, Jabalpur for culture and antimicrobial sensitivity tests. The study was conducted for a period of seven months (October, 2019-April, 2020).

A total of 75 faecal swabs were collected from 08 different species of wild birds. Both captive and free ranging wild birds were included in the present study. A complete list of faecal swabs collected from different sources is presented in Table 1.

Isolation of bacteria faecal swabs were cultured bacteriologically as per Markey et al. (2013) with slight modifications to isolate and identify Escherichia coli and Staphylococcus sp. microscopic examination was carried out by using Gram's staining as per protocol by Tille (2014). The colonies showing typical metallic sheen were selected for Gram's staining for E. coli. Gram negative reaction with short rods were presumptively considered positive for E. coli. The colonies showing typical shiny, jet-black appearance was selected for Gram's staining. Gram positive reaction with cocci grapes like cluster were presumptively considered positive for Staphylococcus sp. Biochemical test was carried out as per protocol mentioned in commercially available test kit $\mathrm{KB} 001^{\mathrm{TM}} \mathrm{HilMViC}$ for $E$. coli and $\mathrm{KB} 004$ HiStaph $^{\mathrm{TM}}$ for Staphylococcus sp.

Antibiogram assay of the isolates was carried out by following Kirby-Bauer disk diffusion method for antibacterial susceptibility test (CLSI, 2013), six antimicrobials each for E. coli and Staphylococcus sp. were selected (Table 2, Table 3).

\section{RESULTS AND DISCUSSION Isolation of bacteria}

A total of 75 faecal samples were collected from captive and free ranging wild birds. Out of 75 samples tested, 58 $(77 \%)$ yielded $E$. coli (Table 4 , Fig 1 ). The inoculum was inoculated in to selective MacConkey agar and incubated at $37^{\circ} \mathrm{C}$ for $18 \mathrm{hrs}$. All the isolates were lactose fermenters as indicated by small bright pink colonies on MacConkey agar medium $=$ and the pink colonies were further inoculated on Eosin Methylene Blue agar and incubated at $37^{\circ} \mathrm{C}$ for 18 hrs. which showed colonies with metallic green sheen. Morphologically, all isolates in Gram's staining revealed pink coloured gram negative rods (Fig 3 ) showing motility in hanging drop method under 40X light microscope. Isolation and identification of the study indicated that the fecal sample contained Gram negative, rod shaped and motile organism with various colony characteristics in different bacteriological media. The isolate was able to produce characteristic pink colony on MacConkey agar and metallic sheen colonies on EMB agar. The colony characteristics of the isolated $E$. coli in different media resemble the colony characteristics of E. coli as stated by Buxton and Fraser (1977), Markey et al. (2013) and Putra et al. (2020).

A total of 75 faecal samples were collected from captive and free ranging wild birds. Out of 75 samples tested, 58 $(77 \%)$ yielded Staphylococcus sp. (Table 4, Fig 2), faecal swabs were cultured on Mannitol Salt Agar and incubated at $37^{\circ} \mathrm{C}$ for $18-24 \mathrm{hrs}$. Presumptive yellow colonies with yellow zone of Staphylococcus sp. were picked up for

Table 1: List of samples collected from different species of captive and free ranging wild birds.

\begin{tabular}{llcc}
\hline Family & Common name (Scientific name) & Total samples & Sample taken \\
\hline Phasianidae & Peafowl (Pavo cristatus) & 20 & Fecal swab \\
Psittaculidae & Parakeet- Rose ringed parakeet (Psittacula krameri) & 23 & Fecal swab \\
& IAlexandrine parakeet (Psittacula eupatria) & 07 & Fecal swab \\
Accipitridae & Egyptian vulture (Neophron percnopterus) & 04 & Fecal swab \\
Strigidae & Eagle owl (Bubo bubo) & 02 & Fecal swab \\
Tytonidae & Barn owl (Tyto alba) & 11 & Fecal swab \\
Accipitridae & Black kite (Milvus migrans) & 07 & Fecal swab \\
Phalacrocoracidae & Little cormorant (Microcarbo niger) & 01 & Fecal swab \\
Accipitridae & Shikra (Accipiter badius) & 75 & \\
& Total & &
\end{tabular}

Table 2: Zone size interpretative chart for antibiotic sensitivity assay for $E$. coli.

\begin{tabular}{|c|c|c|c|c|c|}
\hline \multirow[b]{2}{*}{ Antimicrobial agent } & \multirow[b]{2}{*}{ Symbol } & \multirow[b]{2}{*}{ Concentration $(\mu \mathrm{g})$} & \multicolumn{3}{|c|}{ Diameter of zone of inhibition } \\
\hline & & & $\begin{array}{c}\text { Sensitive } \\
\text { (mm or more) }\end{array}$ & $\begin{array}{l}\text { Intermediate } \\
(\mathrm{mm})\end{array}$ & $\begin{array}{c}\text { Resistant } \\
\text { (mm or less) }\end{array}$ \\
\hline Ampicillin & AMP & $10 \mu g$ & 17 & $14-16$ & 13 \\
\hline Ceftriaxone & CTR & $30 \mu g$ & 23 & $20-22$ & 19 \\
\hline Chloramphenicol & C & $30 \mu g$ & 18 & $13-17$ & 12 \\
\hline Ciprofloxacin & CIP & $05 \mu \mathrm{g}$ & 21 & $16-20$ & 15 \\
\hline Co- trimoxazole & СOT & $25 \mu \mathrm{g}$ & 16 & $11-15$ & 10 \\
\hline Tetracycline & $\mathrm{TE}$ & $30 \mu \mathrm{g}$ & 15 & $12-14$ & 11 \\
\hline
\end{tabular}


selective plating on Baird Parker (egg yolk tellurite) agar (BPA, HiMedia) and incubated at $37^{\circ} \mathrm{C}$ for $18-24 \mathrm{hrs}$. Colonies showing shiny, jet-black (halo around colony) were presumptively considered positive for Staphylococcus sp. Morphologically, all isolates showing Gram positive reaction with cocci grapes like cluster were presumptively considered positive for Staphylococcus sp. (Fig 4).

The biochemical reactions of all the isolates of $E$. coli were found to be positive in catalase, MR and indole tests but negative reaction in VP test and citrate test. The isolates utilized all three sugars glucose, lactose and sucrose which results in acidic slant and butt with gas production which supported the findings of Buxton and Fraser (1977), Markey et al. (2013) and Gupta et al. (2019) similarly Zahera et al. (2011) characterized E. coli from urine samples. The biochemical characters of all $E$. coli observed in present study were in accordance to them. From the total positive samples tested for E. coli phenotypic characterization (Fig 5)

Table 3: Zone size interpretative chart for antibiotic sensitivity assay for Staphylococcus sp.

\begin{tabular}{|c|c|c|c|c|c|}
\hline \multirow[b]{2}{*}{ Antimicrobial agent } & \multirow[b]{2}{*}{ Symbol } & \multirow[b]{2}{*}{ Concentration $(\mu g)$} & \multicolumn{3}{|c|}{ Diameter of zone of inhibition } \\
\hline & & & $\begin{array}{c}\text { Sensitive } \\
\text { (mm or more) }\end{array}$ & $\begin{array}{l}\text { Intermediate } \\
(\mathrm{mm})\end{array}$ & $\begin{array}{c}\text { Resistant } \\
\text { (mm or less) }\end{array}$ \\
\hline $\begin{array}{l}\text { Amoxyclav } \\
\text { (Amoxycillin/clavulanic acid) }\end{array}$ & AMC & $30 \mu \mathrm{g}$ & 36 & $27-35$ & 26 \\
\hline Ceftriaxone & CTR & $30 \mu \mathrm{g}$ & 21 & $14-20$ & 13 \\
\hline Chloramphenicol & C & $30 \mu g$ & 18 & $13-17$ & 12 \\
\hline Clindamycin & CD & $02 \mu \mathrm{g}$ & 21 & $15-20$ & 14 \\
\hline Ofloxacin & OF & $05 \mu g$ & 18 & $15-17$ & 14 \\
\hline Vancomycin & VA & $30 \mu \mathrm{g}$ & 22 & $17-21$ & 16 \\
\hline
\end{tabular}

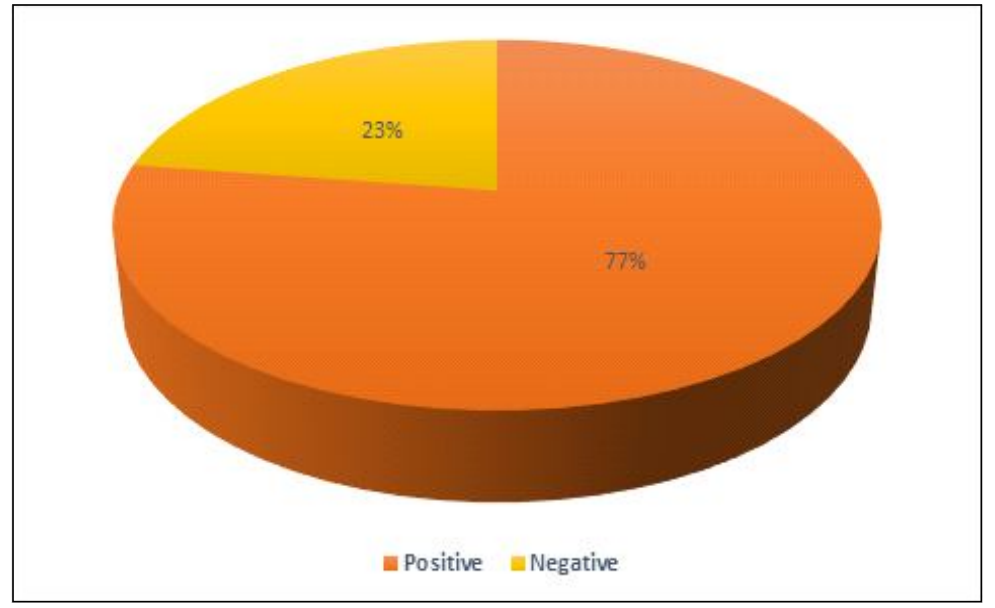

Fig 1: Isolates obtained of $E$. coli from total samples tested.

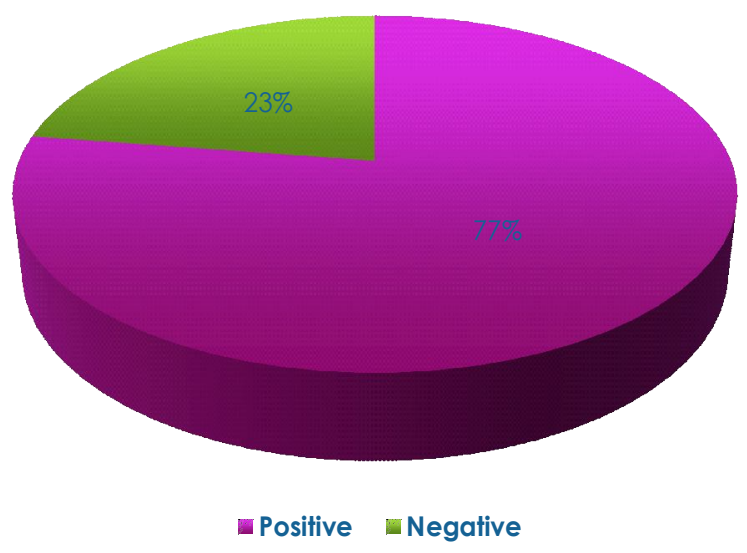

Fig 2: Isolates obtained of Staphylococcus sp. from total samples tested. 
of $53(91.3 \%)$ samples showed typical reactions as mentioned above. Similarly, the isolates of Staphylococcus sp. using HiMedia KB004 HiStaph biochemical test kit, it was found positive for Voges Proskaeur's and Alkaline phosphatase, negative for ONPG. It utilized sugars including mannitol, sucrose, lactose and maltose. From total samples tested, 55 (94.5\%) samples showed typical phenotypic characteristics of Staphylococcus sp. (Fig 6).

\section{Antimicrobial sensitivity tests}

The present study was designed to detect the presence of antimicrobial resistant strains of $E$. coli and Staphylococcus $\mathrm{sp}$. Double disc diffusion test was carried out for $E$. coli

Table 4: Results of Isolates obtained from culture of samples.

\begin{tabular}{lcc}
\hline Bacteria species & Positive & Negative \\
\hline E. coli & 58 & 17 \\
Staphylococcus sp. & 58 & 17 \\
\hline
\end{tabular}

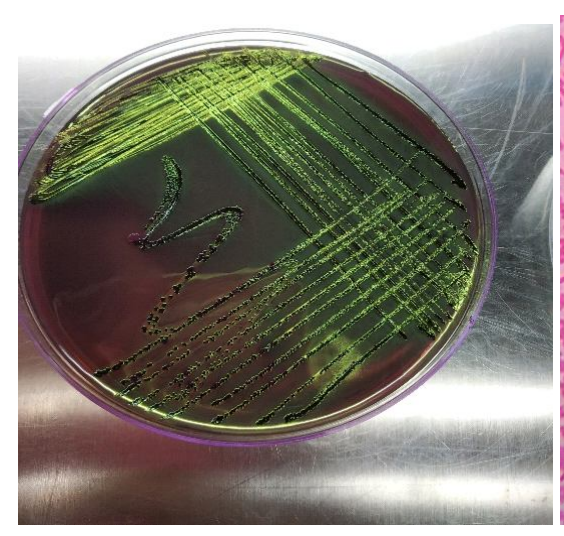

isolates for six antibiotics including Ampicillin, Ceftriaxone, Cotrimoxazole, Chloramphenicol, Ciprofloxacin and tetracycline respectively. Out of the total 58 isolates tested, $15(25.8 \%)$ were found resistant to at least one antimicrobial, $32(55.1 \%)$ were sensitive to all the antimicrobials, 11 (18.9) showed intermediate resistance to at least one antimicrobial. The most commonly resistant antimicrobials were Cotrimoxazole followed by ampicillin, ciprofloxacin and ceftriaxone and tetracycline.

Double disc diffusion test was carried out for E. coli isolates for six antibiotics including ampicillin, ceftriaxone, cotrimoxazole, chloramphenicol, ciprofloxacin and tetracycline respectively. Out of the total 58 isolates tested, $25 \%$ were found resistant to at least one antimicrobial. The multidrug resistance patterns towards different antibiotics in decreasing order were cotrimoxazole $(22.4 \%)$, ampicillin $(8.6 \%)$, ceftriaxone and ciprofloxacin $(3 \%)$, chloramphenicol $(1 \%)$ and tetracycline (0\%) (Fig 7).

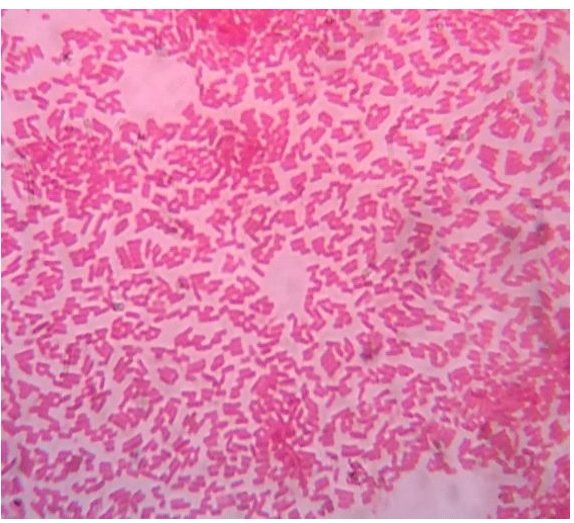

Fig 3: Characteristic features of $E$. coli on agar plate (EMB) and Gram's staining (Gram negative).

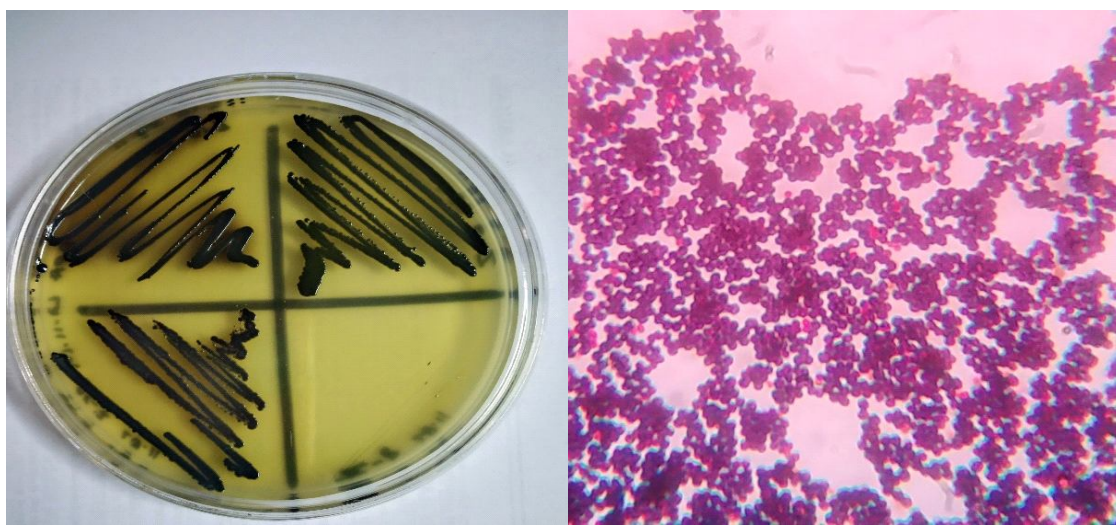

Fig 4: Characteristic features of Staphylococcus sp. on agar plate (BPA) and Gram's staining (Gram positive).

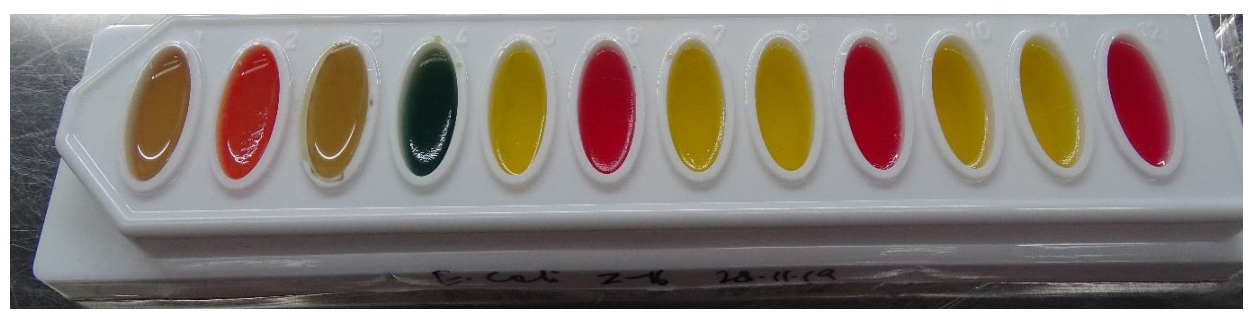

Fig 5: Biochemical identification of E. coli using HiMedia KB001 biochemical test kit. 
Double disc diffusion test was carried out for Staphylococcus sp. isolates for six antibiotics including amoxicillin, ceftriaxone, chloramphenicol, clindamycin, ofloxacin and vancomycin respectively. Out of the total 58 isolates tested, $10 \%$ resistance was observed in Staphylococcus sp. The multidrug resistance patterns towards different antibiotics in decreasing order were Clindamycin $(8 \%)$, Ofloxacin $(1 \%)$ and Ceftriaxone, Amoxicillin, Ciprofloxacin and Vancomycin (0\%) (Fig 8).

Genes encoding bacterial resistance are either intrinsic as a result of vertical transmission or acquired as a result of horizontal gene transmissions. McDanel et al. (2017) reported non virulent bacteria harbouring resistance genes

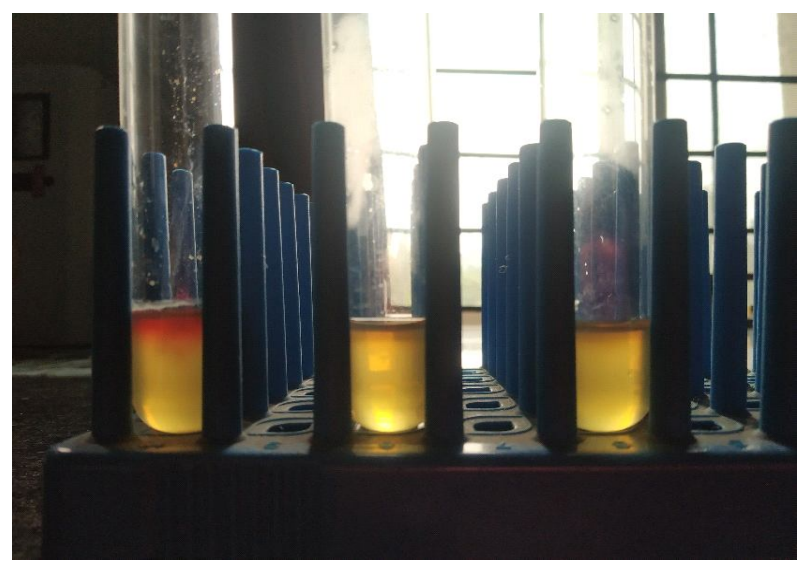

Fig 6: VP Biochemical test for Staphylococcus sp. showing positive reaction indicated by formation of ring at the surface. may present a threat to public health given that genes conferring antimicrobial resistance (AMR) can be transferred to bacterial pathogens via either of the above two mechanisms. Therefore, it is crucial to address the presence of resistant bacterial gene in not only captive wild birds, but also free ranging species of wild birds.

Escherichia coli was first described by Theobald Escherich in 1885 as reported by Sojka, (1965). He examined the feces of new born breast feeding babies and found that they contained bacteria, he called this microorganism as E. coli. Bonnedahl and Jarhult (2014) revealed bbacteria from wild birds can act as a reservoir of antibiotic resistant bacterial genes and as potential spreaders of resistance genes through the ability to migrate long distances over a short period of time. Nelson et al. (2008) studied many wild birds (e.g., Seagulls) and observed they have found to carry the same strain of $E$. coli as isolated from landfills and water treatment plants which demonstrate the transmission between sewage and birds.

Present study detected multidrug resistant $E$. coli and Staphylococcus sp. from faecal samples of captive and free ranging wild birds. These findings indicate a risk of contamination of environment by the resistant bacteria and resistance gene and a matter of public health concern as wild birds have the ability to travel distances. This also recommends vigil monitoring and judicious use of antimicrobials to limit the emergence and dissemination of these bacteria from animals to human and vice versa.

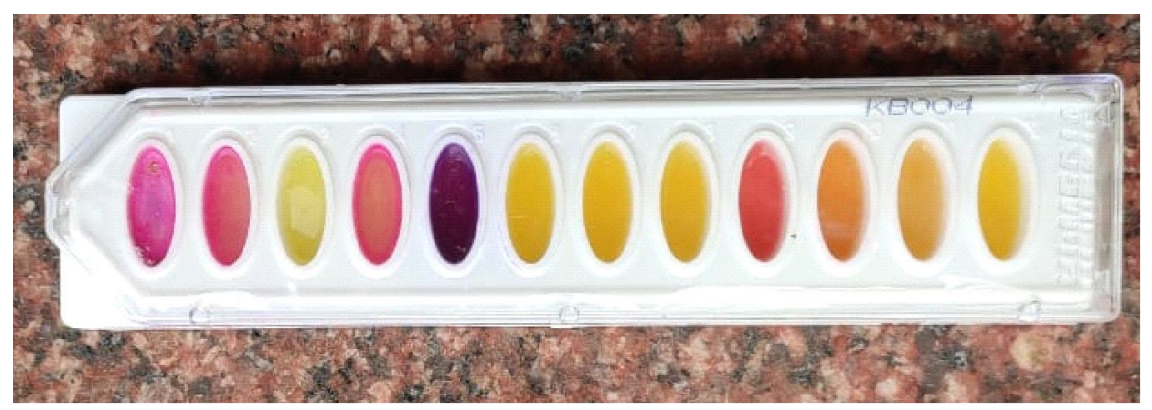

Fig 7: HiStaph Biochemical test kit depicting biochemical properties of Staphylococcus sp.

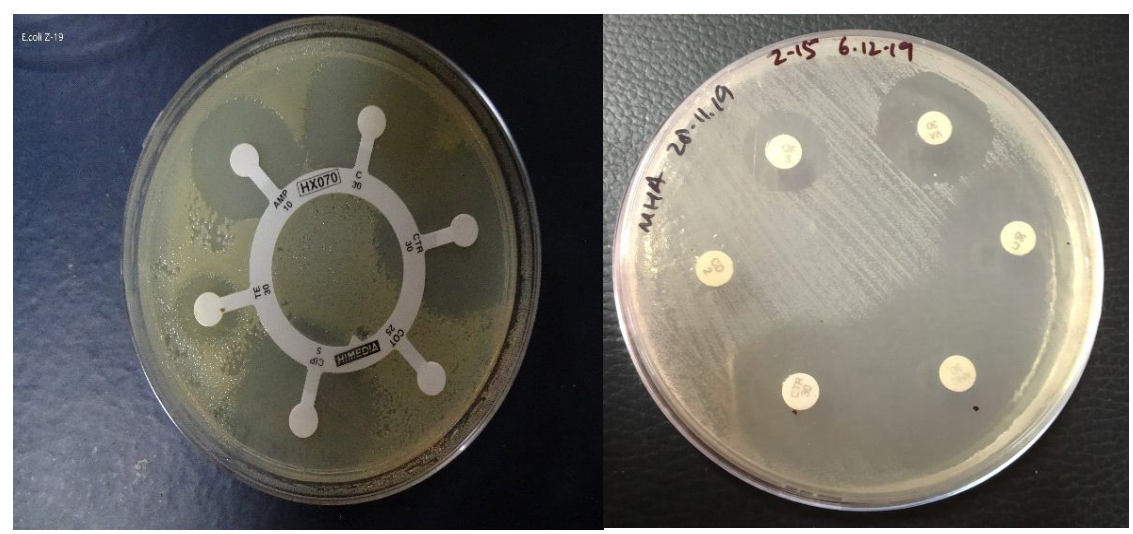

Fig 8: Antimicrobial resistant bacterial isolates of E. coli and Staphylococcus sp. 


\section{CONCLUSION}

Wild animals and birds are facing multiple threats including habitat loss, pollution, poaching, illegal trades. Antimicrobial resistance is another threat for them, especially while some free species have no direct exposure such drugs. Resistance was observed for the commonly used antimicrobials in livestock and humans' consumption by medical professionals. As the study presented its results in the form of 04 tables and 05 figs, risk to antimicrobials have increased. Regulating the use of such medication is the need of the hour.

\section{ACKNOWLEDGEMENT}

The authors would like to extend their gratitude to Director, SWFH, NDVSU, Forest department Madhya Pradesh for their immense support and guidance.

\section{REFERENCES}

Bonnedahl, J. and Jarhult, J.D. (2014). Antibiotic resistance in wild birds. Upsala Journal of Medical Sciences. 119(2): 113-116.

Buxton, A. and Fraser, G. (1977). Animal Microbiology. Escherichia coli. Balckwell Scientific Publications, Oxford, London, Edinburg, Melbourne. 1: 94-102.

CLSI. (2013). Performance Standards for Antimicrobial Susceptibility Testing, Twenty-third edition: Informational Supplement. CLSI Document M100-S23. Clinical and Laboratory Standards Institute, Wayne, PA.

Gupta, S., Abhishek., Shrivastava, S. and Verma, A.K. (2019). Isolation, identification, molecular characterization and antibiogram of $E$. coli isolates from neonatal calves. International Journal of Current Microbiology and Applied Sciences. 8(6): 1996-2007.

Hiltunen, T., Virta, M. and Laine, A.L. (2016). Antibiotic resistance in the wild: An eco-evolutionary perspective. Philosophical Transactions of the Royal Society. 372: 1-20.

Markey, B., Leonard, F., Archambault, M., Cullinane, A. and Maguire, D. (2013). Clinical Veterinary Microbiology, $2^{\text {nd }}$ Edn., Elsevier, Netherlands, 920.

McDanel, J. (2017). Incidence of extended spectrum Beta Lactamase producing E. coli and Klebsiella infections in the US: A systematic literature review. Infection Control and Hospital Epidemiology. 38: 1209-1215.
Nelson, M., Jones, S.H., Edwards, C. and Ellis, J.C. (2008). Characterization of $E$. coli population from Gulls, landfill trash and wastewater using ribotyping. Diseases of Aquatic Organisms. 81: 53-63.

O'Brien, T. (2002). Emergence, spread and environmental effect of antimicrobial resistance: How use of an antimicrobial anywhere can increase resistance to any antimicrobial anywhere else. Clinical Infectious Diseases. 34: 78-84.

Putra, A.R., Effendi, M.H., Koesdarto, S., Suwarno, S., Tyasningsih, W. and Estoepangestie, A.T. (2020). Detection of the extended spectrum $\beta$-lactamase produced by Escherichia coli from dairy cows by using the Vitek-2 method in Tulungagung regency, Indonesia. Iraqi Journal of Veterinary Sciences. 34(1): 203-207.

Radhouani, H., Poeta, P., Pinto, L., Miranda, J., Coelho, C., Carvalho, C., Rodrigues, J., Lo 'pez, M. and Torres, C. (2010). Proteomic characterization of vanA-containing enterococcus recovered from seagulls at the berlengas natural reserve, W Portugal. Journal of Proteome Research. 8: 48.

Sojka (1965). Escherichia coli in Domestic Animals and Poultry, Commonwealth Agricultural Bureaux Publication, pp 231.

Sunder, J., Sujatha, T.S., Bhowmick, S.C., Mayuri, A.K., Bhattacharya, P. and Perumal, A.K. (2021). Distribution of TET, AAC and $C T X-M$ Genes among Antibiotic resistant Escherichia coli Isolated from poultry under various farming system of $\mathrm{A}$ and $\mathrm{N}$ Islands. Indian Journal of Animal Research. 6(55): 689-696.

Tille, P.M. (2014). Bailey and Scott's Diagnostic Microbiology, $13^{\text {th }}$ Edn. Elsevier Mosby Inc., Missouri, USA, pp 193-246.

Van den Bogaard, A.E. and Stobberingh, E.E. (2000). Epidemiology of resistance to antibiotics links between animals and humans. International Journal of Antimicrobial Agents. 14: 327-335.

Von Winterdorff, C.J.H. (2016). Dissemination of antimicrobial resistance in microbial ecosystems through horizontal gene transfer. Frontiers in Microbiology. 7: 173.

Woolhouse, M. and Ward, M. (2013). Sources of Antimicrobial Resistance. Science. 341: 22.

Zahera, M., Rastogi, C., Singh, P., Iram, I., Khalid, S. and Kushwaha, A. (2011). Isolation, identification and characterization of Escherichia coli from urine samples and their antibiotic sensitivity pattern. European Journal of Experimental Biology. 1: 118-124. 